\title{
Intracellular calcium and pathogenesis and antenatal diagnosis of Duchenne muscular dystrophy
}

\author{
A E H EMERY, D BURT
}

\section{Summary and conclusions}

One of the earliest and most important abnormalities of fetal muscle in Duchenne muscular dystrophy is an increase in eosinophilic fibres (those that stain darkly with eosin). A study of normal and at-risk male fetuses after abortion was carried out, which showed that these eosinophilic fibres contain increased intracellular calcium, which suggests that this is an early biochemical change in the disorder.

Since increased intracellular calcium would account for various biochemical and clinical features of the disease, it may be related to the primary defect. Thus an increase in muscle fibres containing increased intracellular calcium in at-risk fetuses may provide an additional means of assessing the validity of any future presumptive antenatal test for Duchenne museular dystrophy.

\section{Introduction}

Duchenne muscular dystrophy is a serious X-linked disorder associated with progressive muscle wasting and weakness. The cause is unknown, but evidence is accumulating of a widespread membrane defect demonstrable not only in muscle tissue but also in lymphocytes and erythrocytes.

We have reported ${ }^{1}$ that in muscle from male fetuses at risk for Duchenne muscular dystrophy the proportion of fibres that stain darkly with eosin and are therefore referred to as eosinophilic fibres is appreciably increased. Since eosinophilic fibres were present in the absence of gross histological changes (for example, necrosis and phagocytosis), we concluded that the increase in these fibres must be one of the earliest structural changes in the disorder. Here we report that these same muscle fibres contain increased intracellular calcium, which therefore suggests that this is an early biochemical change in the disorder. Since increased intracellular calcium would account for many of the membrane abnormalities, and even some of the clinical features associated with this disease, this may be related to the primary defect.

\section{Methods}

Material from normal male fetuses was obtained at the time of therapeutic abortion in casses with no history of any neuromuscular disorder, and from at-risk male fetuses after therapeutic abortion in mothers at high risk of having an affected son. The gestational ages ranged from 14 to 21 weeks in both groups. Pregnancies were terminated by either hysterotomy or prostaglandin, and, at least in controls, the method of termination did not appear to affect the proportions of eosinophilic fibres and muscle fibres containing increased intracellular calcium, which were also unrelated to gestational age.

Specimens of quadriceps muscle were obtained as soon as possible after termination and fetal death. Transverse cryostat sections were stained with haematoxylin and eosin. Serial $10 \mu \mathrm{m}$ sections were also stained for calcium (by using alizarin red $S^{2}$ and a fluorescence method

\footnotetext{
University Department of Human Genetics, Western General

Hospital, Edinburgh EH4 2XU

A E H EMERY, D SC, FRCPE, professor

D BURT, MIBIOL, senior technical officer
}

with pentahydroxyflavone (Morin) ${ }^{3}$ ) and for ferric iron by using Perl's method. ${ }^{4}$ Methods for determining muscle-fibre size and the proportion of eosinophilic fibres have been reported..$^{5}$ Only the central arèas of each section were studied to avoid artefacts, which are commoner toward the periphery of sections.
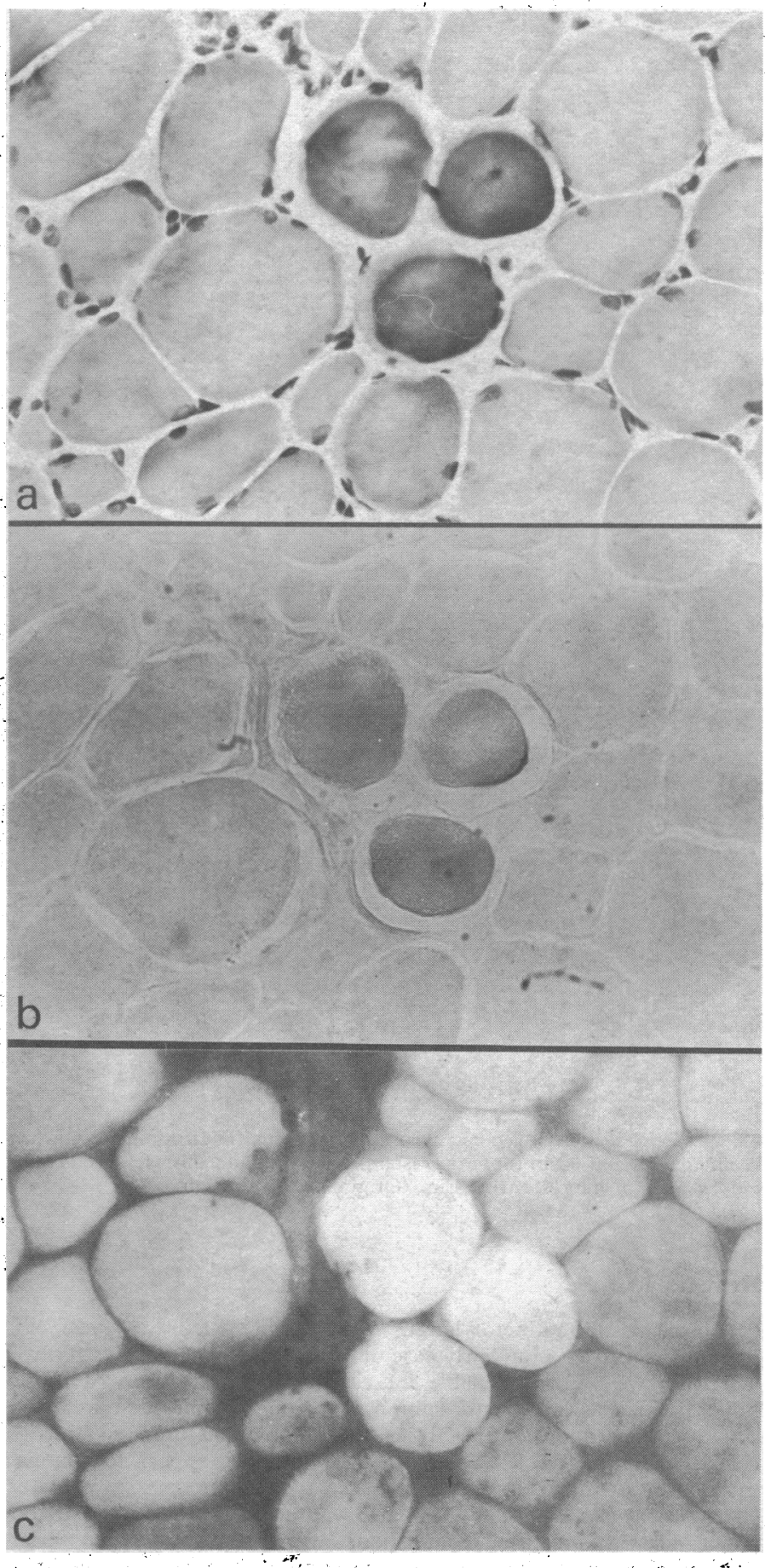

FIG 1-Serial sections of muscle from patient presenting as early case of Duchenne muscular dystrophy, stained with $(a)$ haematoxylin and eosin (note three centrally placed dark-staining eosinophilic fibres); (b) alizarin red $S$; and $(c)$ fluorescent Morin. (Original magnification $\times 430$.) 


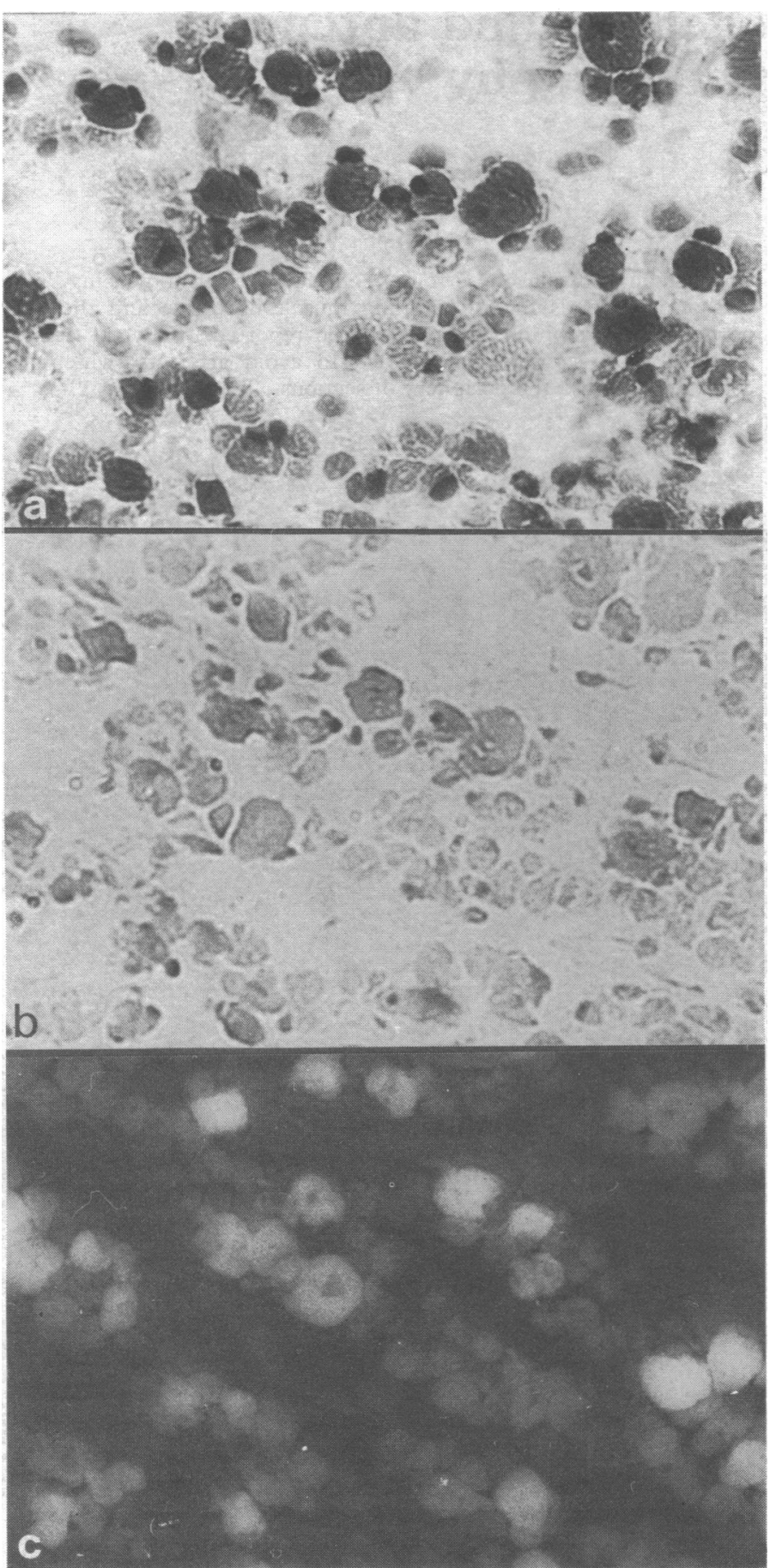

FIG 2-Serial sections of muscle from at-risk fetus (B118) stained with (a) haematoxylin and eosin (note dark-staining eosinophilic fibres); (b) alizarin red $S$; and $(c)$ fluorescent Morin. (Original magnification $\times 740$.)

\section{Results}

Muscle tissue (adductor longus) was examined from a 7-year-old patient presenting as an early case of Duchenne muscular dystrophy, which showed an appreciable increase in the proportion of those fibres defined as large, dark-staining eosinophilic fibres. Staining of serial sections showed that these fibres contained increased intracellular calcium (fig 1). They did not, however, appear to contain increased amounts of iron.

In two at-risk fetuses (B118, B132) previously considered to be abnormal with increased proportions of eosinophilic fibres, ${ }^{1}$ serial sections showed that most of these eosinophilic fibres also contained increased intracellular calcium (fig 2). Occasional muscle fibres that appeared histologically normal, in both at-risk and normal fetuses, also sometimes contained increased calcium. The proportions of fibres containing increased intracellular calcium, however, were greater in these two at-risk fetuses than in the controls (table). There was no apparent increase in the proportions of these fibres in six other at-risk fetuses in which the proportions of eosinophilic fibres and other variables (mean and variance in fibre size) were normal (table). As in the patient with Duchenne muscular dystrophy, the eosinophilic fibres in at-risk fetuses did not contain increased amounts of iron.

Results obtained in muscle from normal and at-risk fetuses. (Values outside normal range given in italics)

\begin{tabular}{|c|c|c|c|c|c|c|}
\hline & \multirow{2}{*}{$\begin{array}{c}\text { Method of } \\
\text { termination }\end{array}$} & \multicolumn{2}{|c|}{ Fibre diameter } & \multirow{2}{*}{$\begin{array}{c}\text { Eosinophilic } \\
\text { fibres } \\
(\%)\end{array}$} & \multicolumn{2}{|c|}{$\begin{array}{c}\text { Fibres containing } \\
\text { increased intracellula } \\
\text { calcium }(\%)\end{array}$} \\
\hline & & $\begin{array}{c}\text { Mean } \\
(\mu \mathrm{m})\end{array}$ & $\underset{\left(\sigma^{2}\right)}{\text { Variance }}$ & & $\begin{array}{l}\text { Alizarin } \\
\text { stain }\end{array}$ & $\begin{array}{l}\text { Morin } \\
\text { stain }\end{array}$ \\
\hline \multicolumn{7}{|c|}{ Ranges in normal fetuses } \\
\hline & $\mathbf{H} / \mathbf{P}$ & $\begin{array}{l}\begin{array}{l}6 \cdot 9-10 \cdot 7 \\
(n=16)\end{array}\end{array}$ & $\begin{array}{l}0 \cdot 8-3 \cdot 6 \\
(n=16)\end{array}$ & $\begin{array}{c}0-5 \cdot 0 \\
(n=16)\end{array}$ & $\begin{array}{c}0-3 \cdot 9 \\
(\mathrm{n}=9)\end{array}$ & $\begin{array}{c}0-7 \cdot 0 \\
(n=9)\end{array}$ \\
\hline \multicolumn{7}{|c|}{ At-risk fetuses } \\
\hline $\begin{array}{l}\text { B118 } \\
\text { B132 }\end{array}$ & $\underset{\mathbf{P}}{\mathbf{H}}$ & $\begin{array}{r}9 \cdot 6 \\
10 \cdot 0\end{array}$ & $\begin{array}{l}2 \cdot 5 \\
4 \cdot 3\end{array}$ & $\begin{array}{l}8 \cdot 0 \\
6 \cdot 9\end{array}$ & $\begin{array}{r}12 \cdot 0 \\
8 \cdot 4\end{array}$ & $\begin{array}{r}10 \cdot 5 \\
7 \cdot 0\end{array}$ \\
\hline $\begin{array}{l}\text { B119 } \\
\text { B125 } \\
\text { B135 } \\
\text { B141 } \\
\text { B142 } \\
\text { B143 }\end{array}$ & $\begin{array}{l}\mathbf{P} \\
\mathbf{P} \\
\mathbf{H} \\
\mathrm{H} \\
\mathrm{H} \\
\mathrm{H}\end{array}$ & $\begin{array}{l}8 \cdot 5 \\
8.5 \\
9 \cdot 4 \\
8 \cdot 3 \\
9 \cdot 0 \\
8 \cdot 7\end{array}$ & $\begin{array}{l}1.3 \\
1.7 \\
1.8 \\
0.9 \\
1.7 \\
2.3\end{array}$ & $\begin{array}{l}1.0 \\
4.9 \\
0.0 \\
0.5 \\
0.5 \\
1.8\end{array}$ & $\begin{array}{l}2 \cdot 0 \\
0 \cdot 0 \\
0 \cdot 5 \\
1 \cdot 0 \\
0 \cdot 0 \\
3 \cdot 8\end{array}$ & $\begin{array}{l}3 \cdot 0 \\
3 \cdot 0 \\
0 \cdot 0 \\
2 \cdot 0 \\
1 \cdot 0 \\
2 \cdot 0\end{array}$ \\
\hline
\end{tabular}

* $\mathrm{H}=$ Hysterotomy. $\mathrm{P}=$ Prostaglandin.

\section{Discussion}

In their histological and histochemical studies Bodensteiner and Engel ${ }^{6}$ showed an increased proportion of non-necrotic muscle fibres containing increased intracellular calcium in biopsy specimens from patients with Duchenne muscular dystrophy compared with controls and patients with various other neuromuscular disorders. We found similar fibres in an early case of Duchenne muscular dystrophy as well as in muscle from two at-risk fetuses presumed to be affected. Since in the fetal material no gross histological changes (for example, necrosis and phagocytosis) were evident, increased intracellular calcium is apparently a very early biochemical change in the disorder. An increase in the calcium content of muscle nuclei ${ }^{7}$ and mitochondria ${ }^{8}$ in dystrophy has been reported, and mitochondrial calcium overload has been suggested as a possible mechanism for cell necrosis in muscle diseases. ${ }^{9}$

The various membrane changes that have been reported in Duchenne muscular dystrophy might be accounted for by increased intracellular calcium; these include echinocyte formation, ${ }^{1011}$ increased potassium efflux ${ }^{1213}$ and reduced deformability in erythrocytes, ${ }^{14}$ and reduced capping in lymphocytes. ${ }^{15}$ In muscle increased intracellular calcium might account for degeneration and increased protein degradation ${ }^{1617}$ and, through enhancement of calcium-activated proteases, ${ }^{18} 19$ lead to muscle necrosis and weakness; and the resultant increase in interaction between myofilaments might account for the development of muscle contractures. Finally, even the efflux of creatine kinase, one of the most consistent features of Duchenne muscular dystrophy, has been induced in vitro in mouse ${ }^{20}$ and human muscle (Anand and Emery, unpublished observations) by increasing the concentration of calcium in the incubating medium.

If increased intracellular calcium is an important factor in the pathogenesis of Duchenne muscular dystrophy several therapeutic approaches are possible. ${ }^{21}$ Though the influx of calcium could be secondary to a generalised membrane defect, ${ }^{22}$ the primary defect might possibly reside in the active extrusion of intracellular calcium ${ }^{23}$ or even in calcium transport per se since uptake of calcium by the sarcoplasmic reticulum is decreased in Duchenne muscular dystrophy. ${ }^{24}$

Our finding of an increased proportion of muscle fibres containing increased intracellular calcium in at-risk fetuses 
provides an additional variable ${ }^{1}$ for determining whether a particular fetus may have been affected and therefore for assessing the validity of any future presumptive antenatal test based on the study of amniotic-fluid cells or fetal blood.

We thank Miss G Dodds and Miss L Andruzczenko for excellent technical help. We are especially grateful to $\mathrm{Mr}$ I Rocker for providing material from control fetuses, and to Prof V Dubowitz and Dr R Harris for providing material from at-risk fetuses. This work was supported by a research grant from the Muscular Dystrophy Group of Great Britain.

\section{References}

1 Emery AEH, Burt D, Dubowitz V, et al. Antenatal diagnosis of Duchenne muscular dystrophy. Lancet $1979 ;$ ii:847-9.

2 Dahl LK. A simple and sensitive histochemical method for calcium. Proc Soc Exp Biol Med 1952;80:474-9.

${ }^{3}$ Pearse AGE. Histochemistry: theoretical and applied. 3rd ed. Edinburgh: Churchill Livingstone, 1972:1137-8,1407.

4 Pearse AGE. Histochemistry: theoretical and applied. 3rd ed. Edinburgh: Churchill Livingstone, 1972:1402.

${ }^{5}$ Emery AEH. Muscle histology and creatine kinase levels in the fetus in Duchenne muscular dystrophy. Nature 1977;266:472-3.

6 Bodensteiner JB, Engel AG. Intracellular calcium accumulation in Duchenne dystrophy and other myopathies: A study of 567000 muscle fibres in 114 biopsies. Neurol 1978;28:439-46.

${ }^{7}$ Maunder CA, Yarom R, Dubowitz V. Electron-microscopic X-ray microanalysis of normal and diseased human muscle. $\mathcal{F}$ Neurol $\mathrm{Sci}$ $1977 ; 33: 323-34$

8 Oberc MA, Engel WK. Ultrastructural localization of calcium in normal and abnormal skeletal muscle. Lab Invest 1977;36:566-77.

9 Wrogemann K, Pena SDJ. Mitochondrial calcium overload: a general mechanism for cell-necrosis in muscle diseases. Lancet 1976 ; :672-3.

10 Dunn MJ. Red blood cell calcium and magnesium: effects upon sodium and potassium transport and cellular morphology. Biochim Biophys Acta 1974 ;352:97-116.
11 White JG. Effects of an ionophore A23187 on the surface morphology of normal erythrocytes. Am 7 Pathol 1974;77:507-18.

12 Dise CA, Goodman DBP, Lake WC, Hodson A, Rasmussen H. Enhanced sensitivity to calcium in Duchenne muscular dystrophy. Biochem Biophys Res Commun 1977;79:1286-92.

${ }^{13}$ Lake W, Rasmussen H, Goodman DBP. Effect of ionophore A23187 upon membrane function and ion-movement in human and toad erythrocytes. $\mathcal{f}$ Membr Biol 1977 ;32:93-113.

14 Kirkpatrick FH, Hillman DG, LaCelle PL. A23187 and red cells: changes in deformability, $\mathrm{K}^{+}, \mathrm{Mg}^{2+}, \mathrm{Ca}^{2+}$ and ATP. Experientia $1975 ; 31: 653-4$.

15 Schreiner GF, Unanue ER. Calcium-sensitive modulation of Ig capping: evidence supporting a cytoplasmic control of ligand-receptor complexes. f Exp Med 1976;143:15-31.

16 Publicover SJ, Duncan CJ, Smith JL. The use of A23187 to demonstrate the role of intracellular calcium in causing ultrastructural damage in mammalian muscle. 7 Neuropath Exp Neurol 1978;37:544-57.

17 Kameyama T, Etlinger JD. Calcium-dependent regulation of protein synthesis and degradation in muscle. Nature 1979:279:344-6.

${ }^{18} \mathrm{Kar}$ NC, Pearson CM. Hydrolytic enzymes and human muscular dystrophy. In: Rowland LP, ed. Pathogenesis of human muscular dystrophies. Amsterdam: Excerpta Medica, 1977:387-94.

19 Neerunjun JS, Dubowitz V. Increased calcium-activated neutral protease activity in muscles of dystrophic hamsters and mice. $\mathcal{f}$ Neurol $\mathrm{Sci}$ 1979;40:105-11.

20 Soybel D, Morgan J, Cohen L. Calcium augmentation of enzyme leakage from mouse skeletal muscle and its possible site of action. Res Commun Chem Pathol Pharmacol 1978;20:317-29.

${ }^{21}$ Duncan CJ. Role of intracellular calcium in promoting muscle damage: a strategy for controlling the dystrophic condition. Experientia $1978 ; 34: 1531-5$.

${ }^{22}$ Carpenter S, Karpati G. Duchenne muscular dystrophy. Plasma membrane loss initiates muscle cell necrosis unless it is repaired. Brain 1979 ;102:147-61.

${ }^{23}$ Godin DV, Bridges MA, Macleod PJM. Chemical compositional studies of erythrocyte membranes in Duchenne muscular dystrophy. Res Commun Chem Path Pharmacol 1978;20:331-49.

24 Samaha FJ. Sarcotubular system in the muscular dystrophies. In: Rowland LP, ed. Pathogenesis of human muscular dystrophies. Amsterdam: Excerpta Medica, 1977:633-9.

(Accepted 8 November 1979)

\section{Summary and conclusions}

Cortisol to creatinine ratios in overnight urine samples, urinary glucose excretion, and plasma glucose concentrations were determined in 43 diabetic inpatients. All initially had normal cortisol to creatinine ratios $\left(<55 \times 10^{-6}\right)$ and were initially treated by increasing their long-acting insulin component. Nine patients in whom this ratio became raised then had their long-acting insulin component reduced until their fasting plasma glucose concentration was 4-7 mol/1 (72-126 mg/100 ml). The 34 patients who had never had a raised ratio were treated by increasing their long-acting insulin component until their fasting plasma glucose concentration was in the range 4-7 mmol/1. All the raised cortisol to creatinine ratios were clearly separate from the other values. A

Nuffield Departments of Medicine and Clinical Biochemistry, Radcliffe Infirmary, Oxford OX2 6HE

C M ASPLIN, MRCP, senior registrar (present address: Diabetes Centre, University of Washington, Seattle, USA)

T D R HOCKADAY, DPHIL, FRCP, consultant physician

R F SMITH, FIMLS, chief medical laboratory scientific officer

R A MOORE, MA, DPHIL, principal biochemist mean reduction in total insulin dose of $23 \%$ and in longacting insulin dose of $53 \%$ was achieved, abolishing presumptive nocturnal hypoglycaemia by reducing the ratio to normal and dramatically improving diabetic control.

Although there was no definite evidence that the patients who had raised cortisol to creatinine ratios had suffered from nocturnal hypoglycaemia, these results strongly support the view that a raised ratio indicates an otherwise unrecognised episode of this condition.

\section{Introduction}

In insulin-treated diabetes the occurrence of fasting hyperglycaemia may be due either to insufficient long-acting insulin to last the night or to overtreatment with insulin, which initially produces hypoglycaemia and then rebound hyperglycaemia. ${ }^{1}$ It is important to distinguish between these two causes of morning hyperglycaemia so that an appropriate alteration in insulin dose can be made. Nocturnal hypoglycaemia may be recognised by the patient or his doctor, but clinical diagnosis may be difficult. ${ }^{2}$ The definitive method of distinguishing between the two possibilities is frequent bloodglucose monitoring during the night; this, however, is not 